\title{
EFEITO DAS OPERAÇÕES DE HEDGE E ESPECULAÇÃO SOBRE A VOLATILIDADE DOS PREÇOS DE COMMODITIES AGRÍCOLAS NOS EUA $^{*}$
}

\author{
VALÉria FARIA dos SANTOS ${ }^{\dagger}$ \\ LEANDRO MACIEL $\ddagger$ \\ Rosangela BALLINI $\S$
}

\begin{abstract}
Resumo
Este artigo investiga o impacto das ações de hedgers e especuladores sobre a volatilidade dos retornos de preços à vista de grãos nos Estados Unidos entre 2000 e 2015 incorporando variações dos contratos futuros em modelos da família GARCH. Para verificar a ação destes agentes ao longo do tempo, os modelos foram estimados de forma recursiva. Adicionalmente, ajustou-se um modelo BEKK-GARCH para verificar os efeitos intermercados. Os resultados mostraram que a atuação de hedgers e especuladores têm impacto moderado sobre os mercados estudados, tendo maior efeito após a crise de 2008 e em momentos de redução da correlação entre as commodities.
\end{abstract}

Palavras-chave: GARCH, BEKK-GARCH, mercados agrícolas, Hedge, especulação.

\begin{abstract}
This article aims to investigate the impact of hedgers and speculators on the grain price returns volatility in the United States between 2000 and 2015 by incorporating the variations from future contracts in GARCH family models. To verify how the impact of these investors over time, the models were recursively estimated. Furthermore, a BEKK-GARCH model was used to analyze inter-market effects. The results showed that hedgers and speculators have a moderate impact on the volatility of agricultural markets, with the most prominent impact being after the 2008 crisis and when the correlation among the commodities decreased.
\end{abstract}

Keywords: GARCH, BEKK-GARCH, agricultural markets, hedge, speculation.

JEL classification: Q10, Q11, Q14, G10.

DOI: http ://dx.doi .org/10.11606/1980-5330/ea155701

\footnotetext{
* O presente trabalho foi realizado com apoio da Coordenação de Aperfeiçoamento de Pessoal de Nível Superior - Brasil (CAPES) - Código de Financiamento 001.

† Universidade Estadual de Campinas (Unicamp). E-mail: valeria.mrg@gmail.com

‡ Universidade Federal de São Paulo (Unifesp). E-mail: maciel.leandro@unifesp.br

$\S$ Universidade Estadual de Campinas (Unicamp). E-mail: ballini@unicamp.br
} 


\section{Introdução}

Ao longo das últimas décadas, mercados de commodities agrícolas registraram vários períodos de intensa oscilação, tanto com tendência de alta, quanto de baixa de preços. Desde o início dos anos 2000, estes mercados têm observado uma escalada de preços que atingiu seu ápice entre os anos de 2008 e 2011, movimento que coincidiu com o aumento no volume de contratos de derivativos destes produtos. A combinação destes dois fenômenos reacendeu a discussão sobre o papel dos mercados futuros sobre os mercados de commodities. Parte da literatura defende que se trata de ferramentas importantes na proteção contra o risco de preços, ao passo que outros apontam seu papel como fonte de instabilidade para os mercados à vista subjacentes. Ainda que não haja consenso na literatura, alguns países já têm adotado políticas para limitar o acesso de agentes não comercias aos derivativos de commodities. Assim, destaca-se a importância de verificar de que forma as variações no número de contratos futuros negociados afetam os preços nos mercados à vista de commodities agrícolas, a fim de fornecer informações adicionais aos formuladores de políticas.

Segundo as estimativas do Banco Mundial, os preços das commodities agrícolas aumentaram cerca de $130 \%$ entre os anos de 2002 e 2008 , indicando o retorno de uma tendência ascendente nesses mercados. Embora o fenômeno tenha atingido as commodities de um modo geral, a ascensão de preços nos mercados agrícolas chama especial atenção da comunidade internacional, uma vez que estes produtos têm grande impacto, afetando os países em níveis macro e microeconômico, por estarem relacionados ao setor de alimentos.

Ao mesmo tempo, o início de 2000 também marca um aumento no volume de investimentos nos mercados de derivativos agrícolas, graças à aprovação do Commodity Futures Modernization Act, que reduziu o poder regulatório da Comissão de Mercados Futuros de Commodities dos EUA (Commodity Futures Trading Commission - CFTC). Estima-se que o volume de investimentos em futuros de commodities agrícolas, entre 2000 e 2008, foi da ordem de US\$300 bilhões (Henriques 2008). Os investimentos em derivativos de commodities agrícolas passaram de um patamar de US\$ 10 bilhões para um nível recorde de US\$ 450 bilhões. O volume dessas transações chegou a ser mais de 20 vezes o das transações com estoques físicos, e os investidores não comerciais, que representavam $25 \%$ do mercado nos anos de 1990, chegaram a abarcar a totalidade do mercado de futuros de commodities como milho, trigo e arroz em 2010 (Paula et al. 2015).

Este movimento nos mercados futuros levou muitos autores a analisar a relação entre a ação dos agentes do mercado de derivativos, como hedgers e, especialmente, especuladores, sobre a volatilidade dos preços nos mercados agrícolas. Pode-se definir hedgers como os agentes que assumem no mercado futuro uma posição oposta àquela que possuem no mercado à vista, sendo essa estratégia uma forma de proteção de variações adversas nos preços. De outra forma, especuladores são os agentes que não têm interesse pela commodity objeto do contrato, mas assumem o risco das posições no mercado de derivativos em decorrência da possibilidade de ganhos financeiros (Bessada 2003, Teixeira 1992).

Avaliar o efeito de hedgers e especuladores sobre mercados agrícolas é uma tarefa complexa, uma vez que não é possível classificá-los dentre os participantes dos mercados de derivativos, ou seja, se suas posições são operações 
de hedge ou se estão especulando. Deste modo, muito da literatura a respeito deste tema busca contornar esta questão utilizando variáveis proxy que sejam capazes de captar a ação destes agentes. Trabalhos como os de CapelleBlancard \& Coulibaly (2011), Manera et al. (2013), Rinden (2015), Andreasson et al. (2016) consideram dados da CFTC a respeito de agentes não comerciais, identificando-os como index traders e os utilizando como variáveis proxy para a atividade especulativa. Porém, este método possui algumas limitações para análises de volatilidade, uma vez que a CFTC disponibiliza tais informações por meio de relatórios semanais, para mercados dos Estados Unidos, o que inviabiliza a aplicação deste método para outros países.

Uma metodologia alternativa para mensurar o impacto dos agentes financeiros sobre mercados de commodities é apresentada em trabalhos como os de Rutledge (1978), Garcia et al. (1986), Bessembinder \& Seguin (1993), Lucia \& Pardo (2010), Bohl \& Stephan (2013), Silveira et al. (2014), Bohl et al. (2018). Neles são utilizados dados diários do número de contratos como uma proxy para a ação de hedgers e especuladores, a partir da hipótese de que estes agentes possuem diferentes horizontes de tempo para manter seus contratos. Segundo Rutledge (1978), Leuthold (1983), Bessembinder \& Seguin (1993), especuladores, em geral, compram e vendem contratos em um curto período, muitas vezes no mesmo dia e, portanto, utilizar o número de contratos negoci$\operatorname{ados}^{1}$ mostra-se como uma forma de medir a atividade especulativa. Por outro lado, hedgers mantêm suas posições por mais tempo. Assim, usar o número de contratos em aberto $^{2}$ é uma forma de medir a atividade destes agentes. Uma vez que as informações sobre o número de contratos são disponibilizadas em frequência diária, sobretudo, em mercados futuros minimamente organizados, esses dados podem ser usados para diversas análises. Neste sentido, este trabalho faz uso dessa metodologia para mensurar a ação de hedgers e especuladores nos mercados de grãos dos Estados Unidos.

Ao analisar o impacto de hedgers e especuladores sobre commodities agrícolas, não se pode deixar de considerar os efeitos intermercados. Como discutido por Malliaris \& Urrutia (1996), Kim \& Doucouliagos (2005), Musunuru (2014), mercados que partilham características comuns em sua produção e comercialização, como os de grãos, transmitem variabilidade de preços entre si. Deste modo, é preciso considerar o efeito de transmissão de volatilidade para que não seja confundido com o decorrente das operações em mercados futuros.

Desta forma, este trabalho tem como objetivo investigar o impacto de agentes financeiros, especificamente hedgers e especuladores, sobre a volatilidade condicional nos mercados de milho, soja e trigo nos Estados Unidos, utilizando dados diários de preços no período de 2000 a 2015. Variáveis representativas das ações desses agentes são inseridas exogenamente na equação que descreve a variância condicional em modelos univariados da família GARCH. A principal contribuição encontra-se em estimar tais modelos recursivamente com uma janela móvel de dados, para que se possa observar os efeitos dos agentes financeiros na volatilidade dos mercados agrícolas ao longo do tempo. Adicionalmente, outra contribuição consiste na estimação de modelos de vo-

\footnotetext{
${ }^{1} \mathrm{O}$ número de contratos negociados representa toda a comercialização de um contrato durante um dia específico.

${ }^{2} \mathrm{O}$ número de contratos em aberto descreve todas as posições de um contrato que, ou não foram equalizadas por uma posição futura oposta, ou foram executadas pela entrega física da commodity.
} 
latilidade condicional multivariados BEKK-GARCH, a fim de verificar se em momentos de maior influência de hedgers e especuladores a dinâmica da volatilidade está associada aos efeitos de transmissão de volatilidade.

Após esta breve introdução, o presente artigo está estruturado como segue. A Seção 2 apresenta uma revisão bibliográfica a respeito das alternativas para mensurar a atuação de hedgers e especuladores. A metodologia é descrita na Seção 3, seguida da apresentação dos resultados e as respectivas discussões na Seção 4. Por fim, a Seção 5 conclui o trabalho e apresenta tópicos para pesquisas futuras.

\section{Revisão da Literatura}

A escalada de preços nos mercados de commodities agrícolas, concomitante com o aumento no número de contratos futuros destes produtos negociados nas últimas décadas, tem levado muitos autores a analisar a influência de agentes financeiros sobre os mercados de commodities. Trabalhos como os de Capelle-Blancard \& Coulibaly (2011), Manera et al. (2013), Rinden (2015), Andreasson et al. (2016) utilizam os dados da CFTC para verificar o impacto da ação de agentes não comerciais sobre mercados de commodities, em geral, avaliando preços futuros. A partir de 2005, a Comissão de Futuros dos Estados Unidos divulga, semanalmente, dados sobre investidores comerciais e não comerciais nestes mercados, além de disponibilizar informações que possibilitam identificar mais de um tipo de investidor não comercial. Apesar de auxiliarem na análise a respeito das mudanças que vêm ocorrendo nos mercados futuros nos últimos anos, cabe ressaltar que a periodicidade dos dados e a disponibilidade para um período mais recente e para o país em questão limitam estudos como os de análises de volatilidade. Por este motivo, alguns trabalhos propõem o uso de formas alternativas para medir a ação de determinados investidores financeiros, com base no pressuposto de que cada agente mantém seus contratos por períodos diferentes.

Neste sentido, Rutledge (1978) apresenta um dos primeiros trabalhos a empregar as informações a respeito dos contratos como forma de mensurar a atividade especulativa nos mercados futuros. Segundo o autor, mudanças no volume de contratos negociados são uma maneira de medir a especulação, uma vez que as transações de hedgers compreendem apenas uma pequena proporção do volume diário. Seus resultados demonstram que o volume de negociações é mais uma resposta do que uma causa das variações de preços.

Partindo deste mesmo pressuposto, Garcia et al. (1986) examinam a causalidade entre o volume de contratos negociados e a volatilidade de preços nos mercados futuros de milho, soja, trigo, óleo de soja e farelo de soja entre 1979 e 1980 nos EUA. Para tanto, os autores usam a razão entre o volume de contratos negociados e o número de contratos em aberto como medida de especulação. De acordo com os resultados obtidos, conclui-se que não é possível definir um padrão de causalidade entre preços e volume de contratos transacionados.

Com o objetivo de avaliar a relação dos contratos em aberto sobre os preços nos mercados de boi gordo e de suínos, Leuthold (1983) usa o número de contratos em aberto como forma de mensurar a atividade de investidores financeiros. Segundo o autor, essa medida seria uma proxy para a ação dos hedgers. Observou-se que os contratos em aberto aumentam sazonalmente, atingindo seu pico imediatamente após a colheita, uma vez que há incerteza 
maior quanto aos preços e estoques. Os resultados encontrados também mostram que não há evidências de que as variações no número de contratos desestabilizam os preços nos mercados analisados.

A partir das mesmas hipóteses a respeito dos contratos em aberto representarem a ação de hedgers e dos contratos negociados traduzirem a atividade especulativa, Bessembinder \& Seguin (1993) incorporam a ideia de componente não esperado. Segundo os autores, a parte esperada dos contratos reflete o início do dia de transações, i.e., aproximadamente o nível do dia anterior, enquanto o componente não esperado captura as mudanças nas transações durante o dia. São utilizados modelos autorregressivos para identificar os componentes esperado e não esperado das séries dos contratos, os quais são incorporados em modelos de volatilidade condicional para oito commodities, com o objetivo de identificar separadamente seus efeitos. Os resultados mostram que os efeitos dos componentes não esperados são maiores do que os dos componentes esperados, especialmente para os contratos negociados.

Baseados no trabalho de Garcia et al. (1986), Lucia \& Pardo (2010) utilizam a razão entre o volume de contratos negociados e o número de contratos em aberto como medida de especulação. Adicionalmente, consideram a razão entre as variações diárias dos contratos em aberto e o volume de contratos negociados como medida alternativa de especulação. São analisados três índices de ações entre 2000 e 2006 com o objetivo de demonstrar as vantagens e desvantagens de cada forma de medir a especulação. Conclui-se que a razão entre as variações diárias dos contratos em aberto e o volume de contratos negociados se configurou como uma medida mais precisa da atividade especulativa.

A mesma metodologia apresentada por Bessembinder \& Seguin (1993) é usada por Bohl \& Stephan (2013) para analisar os efeitos dos componentes esperados e não esperados dos contratos futuros sobre a volatilidade condicional dos mercados americanos de milho, soja, trigo, açúcar, petróleo e gás natural. Os autores utilizam um modelo GARCH e incorporam na equação da variância esses componentes como forma de medir a atividade especulativa. Os resultados não indicam evidências significativas de que a ação de especuladores nos mercados futuros desestabiliza os preços à vista das commodities estudadas.

De modo semelhante, considerando o mercado brasileiro, o trabalho de Silveira et al. (2014) avalia a influência das negociações e da volatilidade dos preços futuros sobre a volatilidade dos preços à vista nos mercados de café arábica e de boi gordo, no período entre 2000 e 2010. Os autores utilizam como medidas alternativas para a ação de hedgers e especuladores variações não esperadas no volume de negociações nos mercados estudados, sendo o componente não esperado obtido como a diferença entre o número de contratos e a média móvel dos 21 dias anteriores. A partir de um modelo VAR, testes de causalidade de Granger, decomposição da variância do erro de previsão, e testes de causalidade na variância baseados na função de correlação cruzada e no multiplicador de Lagrange, os autores mostram que, em geral, variações não esperadas no volume das negociações e a variabilidade dos preços futuros alteram o padrão de volatilidade nos mercados à vista das commodities consideradas.

Santos (2018) também se dedica aos mercados agrícolas brasileiros, mais especificamente boi gordo, café e milho, entre 2000 e 2015. A autora demonstra que hedgers têm impacto significativo nos mercados futuros dos três produtos considerados, enquanto especuladores não têm impacto no mercado fu- 
turo de café. Ainda, indica que o mercado à vista de milho brasileiro é afetado significativamente por ambos os agentes.

O trabalho de Kim (2015) também utiliza as noções de componentes esperado e não esperado para captar a ação de hedgers e especuladores nos mercados de 14 commodities agrícolas e energéticas dos EUA. A autora incorpora essas variáveis à equação da variância das séries em questão, incluindo ainda medidas de controle, como inflação, variação da produção, níveis de estoque, entre outras. Seus resultados atestam que a ação de especuladores reduziu a volatilidade nos mercados à vista das commodities estudadas.

Apesar desses trabalhos tratarem a questão da influência dos agentes financeiros sobre as variações de preços nos mercados de commodities, nenhum deles leva em consideração os efeitos de transbordamento. Como demonstrado por Malliaris \& Urrutia (1996), Kim \& Doucouliagos (2005), Musunuru (2014), mercados agrícolas, especialmente de grãos, estão interligados, de modo que há um transbordamento da volatilidade de um mercado para o outro por conta das respectivas correlações. Ou seja, esse é um aspecto importante a ser levado em consideração ao avaliar a volatilidade nos mercados de grãos, como se pretende neste trabalho, de forma a não confundir o efeito de agentes financeiros com o de transmissão de volatilidade.

Deste modo, este trabalho contribui para o debate a respeito da análise da ação de hedgers e especuladores sobre os mercados de commodities não apenas ao incorporar variáveis responsáveis por captar o impacto de tais agentes em modelos de volatilidade, mas também ao estimar tais modelos recursivamente, o que permite verificar a evolução deste efeito ao longo do tempo. Ademais, este trabalho estima um modelo de volatilidade condicional multivariado, $o$ que permite analisar as relações intermercados nos momentos de maior volatilidade.

\section{Metodologia}

Esta seção descreve os modelos de volatilidade condicional univariados e multivariados. Com base na metodologia apresentada por Garcia et al. (1986), Bessembinder \& Seguin (1993), Lucia \& Pardo (2010), Bohl \& Stephan (2013), Silveira et al. (2014), Bohl et al. (2018), são criadas variáveis para mensurar o efeito de hedgers e especuladores sobre a volatilidade dos mercados de grãos dos Estados Unidos. Tais variáveis são inseridas exogenamente em modelos de volatilidade condicional univariados. A seguir, estimativas recursivas são obtidas para que se possa analisar a evolução da ação (ou impacto) destes agentes ao longo do período estudado. Adicionalmente, utiliza-se um modelo de volatilidade condicional multivariado para analisar se as relações verificadas pelos modelos univariados podem ser decorrentes de efeitos de transbordamento de volatilidade.

\subsection{Modelos de Volatilidade Condicional Univariados}

Modelos de volatilidade condicional univariados são usados, frequentemente, para séries financeiras, como séries de retornos de preços de commodities, por conta de suas características particulares. Séries financeiras, em geral, apresentam distribuições com assimetria diferente de zero e elevados valores de curtose, revelando a presença de caudas pesadas, assim como de agrupamentos de volatilidade (Bueno 2011). 
Neste sentido, modelos de variância condicional, como o autorregressivo de heterocedasticidade condicional (ARCH) proposto por Engle (1982), representam um avanço na modelagem de séries financeiras a partir do início da década de 1980, sendo, posteriormente, generalizados e originando vasta literatura sobre o assunto. A premissa básica do modelo $\mathrm{ARCH}$ é que os retornos de um ativo não são correlacionados serialmente, mas a variância condicional (volatilidade) é uma função quadrática dos retornos passados (Engle 1982). Um modelo $\mathrm{ARCH}(r)$ pode ser representado como:

$$
\begin{gathered}
R_{t}=\sqrt{h_{t}} \epsilon_{t}, \\
h_{t}=\alpha_{0}+\alpha_{1} R_{t-1}^{2}+\ldots+\alpha_{r} R_{t-r}^{2}
\end{gathered}
$$

em que $R_{t}=\ln \left(P_{t}\right)-\ln \left(P_{t-1}\right)$ denota os retornos no instante $t, P_{t}$ o preço em $t$ e $\epsilon_{t}$ corresponde a uma sequência de variáveis aleatórias independentes e identicamente distribuídas (i.i.d.), tal que $\epsilon \mid \Omega_{t-1} \sim N\left(0, h_{t}\right), \Omega_{t-1}$ representa as informações disponíveis até o instante $t-1, h_{t}$ representa a variância condicional e $\alpha_{0}>0$ e $\alpha_{i} \geq 0$ são os parâmetros do modelo a serem estimados.

De acordo com Bueno (2011), modelos $\mathrm{ARCH}(r)$ precisam de muitos parâmetros para obter ajuste adequado. Para contornar esse problema, Bollerslev (1986) propôs o modelo de heterocedasticidade condicional autorregressivo generalizado (GARCH), como uma extensão parcimoniosa do método $\mathrm{ARCH}$. Em um modelo GARCH $(r, s)$, a equação da variância (equação (2)) passa a ser representada por:

$$
h_{t}=\alpha_{0}+\sum_{i=1}^{r} \alpha_{i} R_{t-i}^{2}+\sum_{j=1}^{s} \beta_{j} h_{t-j},
$$

em que $\alpha_{0}>0, \alpha_{i} \geq 0$ e $\beta_{j} \geq 0$ são os parâmetros do modelo a serem estimados, tal que $\sum_{i=1}^{q}\left(\alpha_{i}+\beta_{i}\right) \leq 1 \operatorname{com} q=\max (r, s)$. Estas condições são suficientes para que a variância condicional seja sempre positiva e fracamente estacionária (Bueno 2011).

Um modelo amplamente utilizado na prática consiste do $\operatorname{GARCH}(1,1)$, em que a equação da variância condicional é escrita como:

$$
h_{t}=\alpha_{0}+\alpha_{1} R_{t-1}^{2}+\beta h_{t-1} .
$$

Em um modelo GARCH $(1,1)$, a persistência de longo prazo da volatilidade é definida por $\vartheta_{G}=\alpha_{1}+\beta$. Quanto mais próximo da unidade o valor da persistência, maior o tempo em que um choque sobre a volatilidade leva para se dissipar. Por outro lado, a persistência de curto prazo é medida pelo parâmetro $\beta$, enquanto o parâmetro $\alpha_{1}$ mensura o impacto de choques de curto prazo na variância condicional.

Define-se a meia-vida, $v_{G}$, como o tempo no qual um choque na volatilidade tem seu efeito reduzido em $50 \%$. Em um modelo $\operatorname{GARCH}(1,1)$ ela é calculada de acordo com $v_{G}=\log (0,5) / \log \left(\vartheta_{G}\right)$.

Os modelos ARCH e GARCH supõem que os impactos dos choques aleatórios são simétricos. Porém, como destacado por Bueno (2011), as evidências empíricas contradizem essa ideia, pois, em séries financeiras, choques negativos são seguidos por maiores aumentos na volatilidade do que os positivos. 
Para incorporar essa questão, Zakoian (1994) propôs o modelo de heterocedasticidade condicional autorregressivo generalizado com limiar (TARCH). Em um modelo TARCH $(1,1)$ a variância condicional dos retornos é descrita como:

$$
h_{t}=\alpha_{0}+\alpha_{1} R_{t-1}^{2}+\gamma R_{t-1}^{2} D_{t-1}+\beta h_{t-1}
$$

em que $D_{t-1}$ denota uma variável binária tal que $D_{t-1}=1$, se $R_{t}<0$ (retornos negativos) e $D_{t-1}=0$, quando $R_{t} \geq 0$ (retornos positivos).

Estimativas significativas de $\gamma$ indicam a presença de assimetria na volatilidade das séries dos retornos dos preços. Em modelos TARCH, como na equação (5), o efeito de um choque $\left(R_{t-1}^{2}\right)$ negativo na volatilidade $\left(h_{t}\right)$ é dado por $\left(\alpha_{1}+\gamma\right)$, enquanto um choque positivo tem impacto de tamanho $\alpha_{1}$ (pois $D_{t-1}=0$ ). Portanto, de acordo com o sinal de $\gamma$, a assimetria (ou o efeito de choques negativos) é interpretada de forma distinta. Um $\gamma$ positivo (negativo) indica que choques negativos têm maior (menor) influência sobre a dinâmica da variância condicional. Com valores negativos de $\gamma$, choques positivos afetam a variância condicional em proporção maior do que choques negativos, $o$ que caracteriza o efeito inventário (inventory effects).

Efeitos de inventário se baseiam na teoria da estocagem, em que um aumento no preço pode refletir uma deterioração dos estoques de commodities, uma vez que um choque positivo nos preços pode, portanto, indicar uma probabilidade crescente de falta de estoque destes produtos (queda na oferta), isto é, maior impacto assimétrico de choques positivos (Carpantier 2010). O efeito de inventário então se mostra como um sinal do nível de estoques, o que gera, em consequência, um aumento na volatilidade. Choques negativos nos preços, por outro lado, revelam que a oferta excede a demanda, o que reduz a volatilidade.

A persistência de longo prazo da volatilidade no modelo $\operatorname{TARCH}(1,1)$ é dada por $\vartheta_{T}=\alpha_{1}+0,5 \gamma+\beta$, enquanto a meia-vida é calculada similarmente como $v_{T}=\log (0,5) / \log \left(\vartheta_{T}\right)$.

Para mensurar os efeitos da ação de hedgers e especuladores na volatilidade dos retornos das commodities agrícolas, são adotadas também hipóteses de Rutledge (1978), Garcia et al. (1986), Leuthold (1983). Assim, o volume dos contratos negociados é usado para medir a atividade especulativa, uma vez que especuladores não mantêm, em geral, contratos por períodos maiores que um dia, enquanto o número de contratos em aberto é usado para representar a ação dos hedgers, dado que esses agentes costumam manter suas posições no mercado por mais tempo. Também incorpora-se a hipótese de Bessembinder \& Seguin (1993), de que o componente não esperado da variação destes contratos tem impacto maior sobre a volatilidade. Assim como Silveira et al. (2014), neste artigo o componente não esperado dos contratos negociados ( $\mathrm{CNCN}) \mathrm{e}$ o componente não esperado dos contratos em aberto (CNCA) são calculados a partir da diferença entre o volume atual dos contratos, negociados e em aberto, e uma média móvel do número de contratos nos 180 dias úteis anteriores ${ }^{3}$.

Adicionalmente, variáveis de controle foram também incorporadas à equação da variância com o objetivo de capturar o efeito da sazonalidade (períodos de safra) e de evitar vieses nos efeitos das variáveis relacionadas às operações

\footnotetext{
${ }^{3}$ Também foram calculados os componentes CNCN e CNCA com média móvel de 21 e 90 dias úteis anteriores. Porém, como as estimativas dos parâmetros associados às variáveis $\mathrm{CNCN}$ e CNCA com média móvel de 180 dias apresentaram resultados com um melhor ajuste, optou-se por sua utilização.
} 
de hedge e especulação. Assim, foram construídas três variáveis binárias: $D 1$ com valor um para os meses de janeiro, fevereiro e março, e zero para os demais; D2 igual a um para os meses de abril, maio e junho, e zero para os demais; e $D 3$ com valor um para os meses de julho, agosto e setembro, e zero para os demais.

Define-se $\mathrm{CNCA}_{t}$ e $\mathrm{CNCN}_{t}$ como variáveis calculadas a partir da diferença entre o volume atual de contratos em aberto e negociados, respectivamente, e a média móvel do volume de contratos no instante $t$. Portanto, a variância condicional nos modelos $\operatorname{GARCH}(1,1)$ e TARCH $(1,1)$ pode ser obtida da seguinte forma, respectivamente:

$$
\begin{array}{r}
h_{t}=\alpha_{0}+\alpha_{1} R_{t-1}^{2}+\beta h_{t-1}+\theta \mathrm{CNCA}_{t}+\delta \mathrm{CNCN}_{t}+ \\
+\omega_{1} \mathrm{D} 1_{t}+\omega_{2} \mathrm{D} 2_{t}+\omega_{3} \mathrm{D} 3_{t} \\
h_{t}=\alpha_{0}+\alpha_{1} R_{t-1}^{2}+\gamma R_{t-1}^{2} D_{t-1}+\beta h_{t-1}+\theta \mathrm{CNCA}_{t}+ \\
+\delta \mathrm{CNCN}_{t}+\omega_{1} \mathrm{D} 1_{t}+\omega_{2} \mathrm{D} 2_{t}+\omega_{3} \mathrm{D} 3_{t}
\end{array}
$$

em que $\theta$ e $\delta$ são parâmetros a serem estimados e que, se forem significativos, indicam a influência dos hedgers e especuladores na volatilidade dos retornos, respectivamente. Vale destacar que o sinal de tais parâmetros indica a relação dessa influência na variância condicional. Alternativamente, $\omega_{1}, \omega_{2}, \omega_{3}$ são os parâmetros associados às variáveis binárias.

Os modelos $\operatorname{GARCH}(1,1)$ e TARCH $(1,1)$, foram estimados por meio do método de máxima verossimilhança condicional. Dentre as duas técnicas, o método TARCH foi adotado quando a estimativa do parâmetro $\gamma$ mostrouse significativa. Os modelos também foram estimados recursivamente, por máxima verossimilhança. Com base em Silveira et al. (2017) neste trabalho considerou-se uma janela móvel de 1.008 observações, equivalente a quatro anos de dados. A estimação recursiva é uma técnica que processa as informações sequencialmente, fornecendo novas estimativas para as variáveis desejadas a cada iteração. A adoção dessa metodologia permite a análise das estimativas analisar as dos parâmetros $\theta$ e $\delta$ ao longo do tempo, isto é, captura as variações dos efeitos dos hedgers e especuladores, respectivamente, ao longo do período estudado.

\subsection{Modelos de Volatilidade Condicional Multivariados}

Com o objetivo de analisar também a transmissão da volatilidade nas séries dos retornos das commodities analisadas, ajustou-se um modelo de volatilidade condicional multivariado, i.e., um GARCH multivariado. Modelos de volatilidade multivariados são uma extensão dos modelos univariados da família $\mathrm{ARCH}$, tendo como principal diferença a consideração de relações que capturam como as covariâncias se movem conjuntamente ao longo do tempo (Brooks 2008, Engle 2002).

Um dos problemas discutidos na literatura dos modelos da família GARCH multivariados consiste no elevado número de parâmetros a serem estimados. Para tratar essa questão, diversas formulações de modelos de volatilidade condicional multivariados foram propostas, das quais destacam-se os métodos: 
VECH, BEKK, Modelo com correlação constante, modelos de correlação condicional dinâmica e modelo de covariância dinâmica geral (Brooks 2008, Harris \& Sollis 2003, Tsay 2005).

Neste trabalho, adotou-se o modelo BEKK, caso especial do modelo VECH. Na formulação do modelo BEKK, proposta por Engle \& Kroner (1995), é garantida que a matriz de covariância seja positiva semidefinida em cada momento do tempo, além de reduzir os números de parâmetros estimados quando comparado com o modelo VECH (Bueno 2011).

Nos modelos GARCH multivariados, a sequência de erros aleatórios $\left\{\epsilon_{t}\right\}$ é representada por um vetor estocástico de ordem $N \times 1$, em que $N$ é o número de observações, com $E\left(\epsilon_{t} \mid \Omega_{t-1}\right)=0$ e matriz de covariância condicional $E\left(\epsilon_{t} \epsilon_{t}^{\prime} \mid \Omega_{t-1}\right)=H_{t}$.

Um modelo GARCH multivariado pode ser então formulado como:

$$
R_{t}=\sqrt{H_{t}} \epsilon_{t}
$$

sendo $\left\{R_{t}\right\}$ uma sequência $(N \times 1)$ de retornos e $H_{t}$ uma matriz $(n \times n)$, sendo $n$ o número de ativos, e representada por:

$$
H_{t}=\left[\begin{array}{cccc}
h_{11, t} & h_{12, t} & \ldots & h_{1 n, t} \\
h_{21, t} & h_{22, t} & \ldots & h_{2 n, t} \\
\vdots & \vdots & \ddots & \vdots \\
h_{n 1, t} & h_{n 2, t} & \ldots & h_{n n, t}
\end{array}\right]
$$

Os elementos da diagonal principal de $H_{t}$ são as respectivas variâncias e os demais elementos correspondem aos termos de covariância dois a dois. Como a matriz $H_{t}$ é simétrica, Bollerslev et al. (1988) estenderam o modelo GARCH univariado para o caso multivariado, aplicando um operador composto pelos elementos da parte do triângulo inferior dessa matriz, denominado Vech, surgindo, assim, o modelo $\mathrm{VECH}$, descrito a seguir.

\section{O Modelo VECH}

O operador Vech é obtido a partir do empilhamento dos elementos da parte triangular inferior da matriz simétrica $H_{t}$, resultando em um vetor de dimensão $(n(n+1) / 2) \times 1$ (Bueno 2011). é construído a partir do empilhamento das colunas da matriz $H_{t}$ (equação (9)), ou seja:

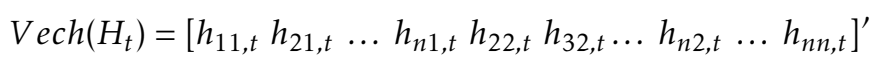

Assim, o modelo GARCH multivariado, obtido após a aplicação do operador Vech, é representado por:

$$
\operatorname{Vech}\left(H_{t}\right)=C+\sum_{i=1}^{q} A_{i} \operatorname{Vech}\left(\epsilon_{t-i} \epsilon_{t-i}^{\prime}\right)+\sum_{j=1}^{p} B_{j} \operatorname{Vech}\left(H_{t-j}\right)
$$

em que $C$ é um vetor $(n(n+1) / 2) \times 1 ; A_{i}$ e $B_{j}$ são $q$ e $p$ matrizes de dimensão $(n(n+1) / 2) \times(n(n+1) / 2)$, respectivamente.

Dada a complexidade desse modelo, para simplificar a explanação, supõese duas séries de retornos. Assim, a matriz $H_{t}$ fica:

$$
H_{t}=\left[\begin{array}{ll}
h_{11, t} & h_{12, t} \\
h_{21, t} & h_{22, t}
\end{array}\right]
$$


Nesse caso, o operador Vech é representado por:

$$
\operatorname{Vech}\left(H_{t}\right)=\left[\begin{array}{lll}
h_{11, t} & h_{21, t} & h_{22, t}
\end{array}\right]^{\prime}
$$

em que $h_{11, t}$ e $h_{22, t}$ são as variâncias de cada série de retornos, e $h_{21, t}$ é a covariância entre elas. Nesse sentido, o modelo na equação (11) é representado, em termos matriciais, por:

$$
\begin{aligned}
{\left[\begin{array}{l}
h_{11, t} \\
h_{21, t} \\
h_{22, t}
\end{array}\right]=} & {\left[\begin{array}{l}
c_{11} \\
c_{21} \\
c_{31}
\end{array}\right]+\left[\begin{array}{lll}
a_{11} & a_{12} & a_{13} \\
a_{21} & a_{22} & a_{23} \\
a_{31} & a_{32} & a_{33}
\end{array}\right]\left[\begin{array}{c}
\epsilon_{1 t-1}^{2} \\
\epsilon_{1 t-1} \epsilon_{2 t-1} \\
\epsilon_{2 t-1}^{2}
\end{array}\right]+} \\
& +\left[\begin{array}{lll}
b_{11} & b_{12} & b_{13} \\
b_{21} & b_{22} & b_{23} \\
b_{31} & b_{32} & b_{33}
\end{array}\right]\left[\begin{array}{l}
h_{11, t-1} \\
h_{21, t-1} \\
h_{22, t-1}
\end{array}\right]
\end{aligned}
$$

Observa-se que as covariâncias condicionais dependem dos valores defasados das variâncias condicionais e das covariâncias condicionais entre as séries, como também dos atrasos dos erros ao quadrado e de seus coprodutos.

Mesmo no caso de dois ativos, as equações da variância e da covariância condicional, em um modelo VECH irrestrito, contêm 21 parâmetros. Caso seja considerado um maior número de ativos, a estimação do modelo pode se tornar inviável. Além do elevado número de parâmetros a ser estimado, outra desvantagem do modelo VECH é que não há garantia da obtenção de uma matriz de covariância positiva semidefinida, que assegura que a matriz terá todos os elementos positivos na diagonal principal e será uma matriz simétrica. Ou seja, a determinação positiva garante que a variância nunca será negativa e que as covariâncias entre as séries são as mesmas, independentemente da ordem selecionada (Brooks 2008). Para contornar tal questão, Engle \& Kroner (1995) propuseram uma representação alternativa ao modelo VECH, denominado modelo BEKK. ${ }^{4}$

\section{O Modelo BEKK}

Para garantir que a matriz de covariância seja positiva semidefinida em cada instante de tempo, Engle \& Kroner (1995) sugeriram uma formulação alternativa, menos restritiva que o VECH, denominada modelo BEKK (Brooks 2008). A ideia básica do modelo consiste em considerar todos os parâmetros na seguinte forma quadrática:

$$
H_{t}=C^{\prime} C+\sum_{i=1}^{q} A_{i}^{\prime}\left(\epsilon_{t-i} \epsilon_{t-i}^{\prime}\right) A_{i}+\sum_{j=1}^{p} B_{j}^{\prime}\left(H_{t-j}\right) B_{j}
$$

em que $A$ e $B$ são matrizes de parâmetros, ambas com dimensão $n \times n$, e $C$ é uma matriz triangular superior.

Para o caso bivariado, o modelo BEKK é representado por:

\footnotetext{
${ }^{4} \mathrm{O}$ termo BEKK surgiu do trabalho Multivariate Simultaneous Generalized Autoregressive Conditional Heteroskedasticity de Yoshi Baba, Robert Engle, Dennis Kraf e Ken Kroner que antecede o artigo de (Engle \& Kroner 1995).
} 


$$
\begin{array}{r}
{\left[\begin{array}{ll}
h_{11, t} & h_{12, t} \\
h_{21, t} & h_{22, t}
\end{array}\right]=\left[\begin{array}{cc}
c_{11} & 0 \\
c_{21} & c_{22}
\end{array}\right]^{\prime}\left[\begin{array}{cc}
c_{11} & 0 \\
c_{21} & c_{22}
\end{array}\right]+\left[\begin{array}{ll}
a_{11} & a_{12} \\
a_{21} & a_{22}
\end{array}\right]} \\
{\left[\begin{array}{cc}
\epsilon_{1 t-1}^{2} & \epsilon_{1 t-1} \epsilon_{2 t-1} \\
\epsilon_{2 t-1} \epsilon_{1 t-1} & \epsilon_{2 t-1}^{2}
\end{array}\right]\left[\begin{array}{ll}
a_{11} & a_{12} \\
a_{21} & a_{22}
\end{array}\right]+\left[\begin{array}{ll}
b_{11} & b_{12} \\
b_{21} & b_{22}
\end{array}\right]} \\
{\left[\begin{array}{ll}
h_{11, t-1} & h_{12, t-1} \\
h_{21 t-1} & h_{22, t-1}
\end{array}\right]\left[\begin{array}{ll}
b_{11} & b_{12} \\
b_{21} & b_{22}
\end{array}\right]}
\end{array}
$$

Nota-se que, no caso de duas variáveis $(n=2)$ e de um modelo de ordem $p=1$ e $q=1$, a representação do modelo BEKK requer a estimação de 11 parâmetros. Ademais, no modelo BEKK as variâncias condicionais individuais $h_{11, t-1}$ e $h_{22, t-1}$ afetam a evolução do termo de covariância $h_{12, t}$.

\subsection{Dados}

As séries de preços a serem analisadas neste trabalho são de cotações diárias, à vista, em US\$/bushel, para o período de janeiro de 2000 a dezembro de 2015, da praça de Central Illinois, para os mercados de milho e soja, e da praça de Toledo, Ohio, para o mercado de trigo. Ambas praças são consideradas referências de preço à vista nos Estados Unidos em seus respectivos mercados. Os dados são disponibilizados pelo Departamento de Agricultura dos Estados Unidos (USDA) (www.marketnews.usda.gov/mnp/ls-home). Para construção das variáveis que objetivam captar a ação de hedgers e especuladores, são utilizadas séries diárias do volume de contratos futuros em aberto e efetivamente negociados, respectivamente, ambos comercializados na Chicago Board of Trade $e^{5}$.

A Tabela 1 apresenta as principais estatísticas descritivas das séries dos retornos dos preços, tais como média, desvio-padrão, máximo e mínimo, assimetria, curtose, em conjunto com a estatística e p-valor do teste de normalidade Jarque-Bera ${ }^{6}$. Tais resultados trazem evidências da adequação de modelos da família GARCH, capazes de capturar os principais fatos estilizados de séries financeiras.

A Figura 1 mostra a evolução dos preços e dos respectivos retornos nos mercados de milho, soja e trigo. Pode-se observar que a trajetória dos preços e o padrão dos retornos são semelhantes e, para todos os mercados, as séries de preços exibem um comportamento volátil. Desde o início do período observase um movimento ascendente de preços que se acentua a partir de 2006, com subsequente queda em 2008, em decorrência da crise, situação que permaneceu até meados de 2010. A partir desse ano, os preços retomam tendência crescente, chegando a seu ápice e voltando a cair por volta de 2012. Observase que os retornos apresentam agrupamentos de volatilidade em momentos de maior variação nos preços, com dinâmicas similares entre os mercados. Apesar de todos os mercados em análise sofrerem quedas nos preços, tais impactos são menos acentuados para a soja.

\footnotetext{
${ }^{5}$ Os dados de número de contratos foram obtidos na plataforma Bloomberg.

${ }^{6}$ Observa-se na Tabela 1 que as séries de milho e soja apresentam distribuição assimétrica à esquerda e a série de trigo tem distribuição assimétrica à direita. Os valores de curtose, todos maiores que três, são indícios da presença de caudas pesadas, ou seja, há evidências de que as séries de retornos são leptocúrticas em relação à distribuição normal. Os valores das estatísticas associadas ao teste de Jarque-Bera confirmam a hipótese de não normalidade dos retornos.
} 
Tabela 1: Estatísticas descritivas das séries dos retornos diários dos preços à vista do milho, soja e trigo, negociados nos EUA

\begin{tabular}{l|r|r|r}
\hline & Milho & \multicolumn{1}{|c}{ Soja } & \multicolumn{1}{c}{ Trigo } \\
\hline Média & 0,000221 & 0,000172 & 0,000248 \\
Desvio-pad. & 0,019280 & 0,016547 & 0,022752 \\
Máximo & 0,094708 & 0,075730 & 0,123845 \\
Mínimo & $-0,118418$ & $-0,131820$ & $-0,125163$ \\
Assimetria & $-0,202594$ & $-0,713456$ & 0,104870 \\
Curtose & 5,654479 & 7,740164 & 5,612315 \\
Jarque-Bera & 1143,755 & 3887,142 & 1090,610 \\
Prob. & 0,000000 & 0,000000 & 0,000000 \\
\hline
\end{tabular}

Figura 1: Preços à vista e retornos dos mercados de milho, soja e trigo dos EUA

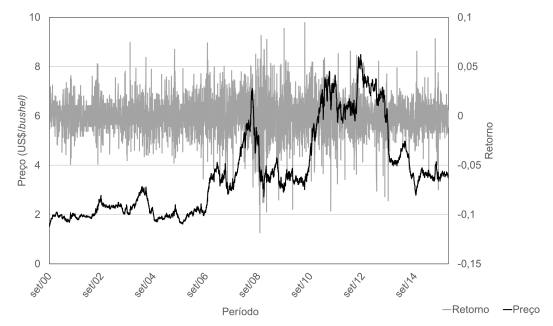

(a) Mercado de milho

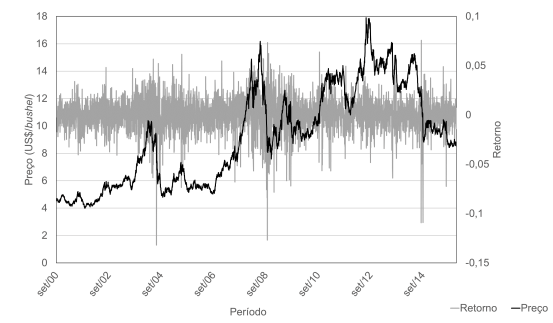

(b) Mercado de soja

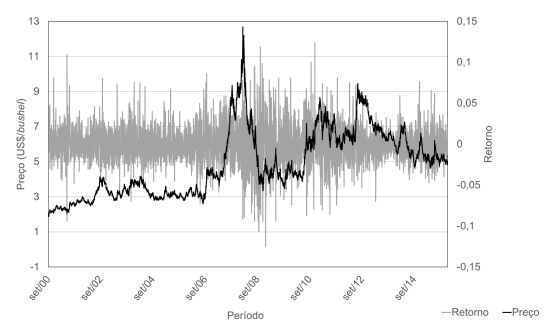

(c) Mercado de trigo

\section{Resultados e Discussão}

\subsection{Modelos de Volatilidade Condicional Univariados}

Esta seção apresenta os resultados referentes aos modelos de volatilidade condicional univariados. Para todas as séries, foram ajustados os modelos GAR$\mathrm{CH}(1,1)$ e TARCH$(1,1)$. A escolha do modelo de volatilidade mais adequado foi baseada na significância estatística do parâmetro $\gamma$, que está associado à assimetria na volatilidade (equação (5)).

Foram adotados o modelo $\mathrm{GARCH}(1,1)$ para as séries dos retornos de milho e trigo, uma vez que os parâmetros $\gamma$ associados à assimetria não apresentaram estimativas significativas, indicando que choques negativos e positivos têm mesmo efeito sobre os retornos destas séries. Para a série de soja, a estimativa do parâmetro $\gamma$ foi significativamente diferente de zero, o que permite 
inferir a presença de assimetria na volatilidade, de forma que se adotou um modelo TARCH $(1,1)$.

A Tabela 2 apresenta as estimativas dos parâmetros dos modelos de variância condicional para as séries dos retornos dos preços à vista para os mercados de milho, soja e trigo no período de janeiro de 2000 a dezembro de 2015. Os valores entre parênteses representam os p-valores das estimativas.

Tabela 2: Estimativas dos parâmetros dos modelos $\operatorname{GARCH}(1,1) / \mathrm{TARCH}(1,1)$

\begin{tabular}{c|c|c|c}
\hline & Milho & Soja & Trigo \\
\hline$\alpha_{0}$ & $\begin{array}{c}-2,11 E-07 \\
(0,7429)\end{array}$ & $\begin{array}{c}1,04 E-06 \\
(0,1322)\end{array}$ & $\begin{array}{c}1,59 E-06 \\
(0,0418)\end{array}$ \\
\hline$\alpha_{1}$ & $\begin{array}{c}0,028297 \\
(0,0000)\end{array}$ & $\begin{array}{c}0,052051 \\
(0,0000)\end{array}$ & $\begin{array}{c}0,035315 \\
(0,0000)\end{array}$ \\
\hline$\beta$ & $\begin{array}{c}0,964516 \\
(0,0000)\end{array}$ & $\begin{array}{c}0,944029 \\
(0,0000)\end{array}$ & $\begin{array}{c}0,959058 \\
(0,0000)\end{array}$ \\
\hline$\gamma$ & - & $\begin{array}{c}-0,016676 \\
(0,0150)\end{array}$ & - \\
\hline$\theta$ & $\begin{array}{c}-7,21 E-12 \\
(0,0349)\end{array}$ & $\begin{array}{c}-2,73 E-11 \\
(0,0026)\end{array}$ & $\begin{array}{c}-1,81 E-11 \\
(0,1275)\end{array}$ \\
\hline$\delta$ & $3,18 E-11$ & $2,86 E-11$ & $9,46 E-11$ \\
$(0,0400)$ & $(0,2415)$ & $(0,1126)$ \\
\hline$\omega_{1}$ & $\begin{array}{c}2,58 E-06 \\
(0,0001)\end{array}$ & $\begin{array}{c}1,86 E-06 \\
(0,0063)\end{array}$ & $\begin{array}{c}2,69 E-06 \\
(0,0037)\end{array}$ \\
\hline$\omega_{2}$ & $\begin{array}{c}5,17 E-06 \\
(0,0000)\end{array}$ & $\begin{array}{c}2,11 E-06 \\
(0,0005)\end{array}$ & $\begin{array}{c}2,10 E-06 \\
(0,0422)\end{array}$ \\
\hline$\omega_{3}$ & $\begin{array}{c}3,29 E-06 \\
(0,0004)\end{array}$ & $\begin{array}{c}5,60 E-06 \\
(0,0000)\end{array}$ & $\begin{array}{c}1,86 E-07 \\
(0,8625)\end{array}$ \\
\hline$\vartheta$ & 0,992813 & 0,987742 & 0,994373 \\
\hline$\nu$ & 96 & 56 & 123 \\
\hline & & & 5 \\
\hline
\end{tabular}

Acerca dos impactos de choques sobre a variância nos mercados, medidos pelo parâmetro $\alpha_{1}$, nota-se que o mercado de soja é o mais afetado, ou seja, dado um choque nos preços, um maior aumento na volatilidade é verificado. O mercado de trigo é o segundo mais sensível a choques de curto prazo, seguido pelo mercado de milho (Tabela 2).

Quanto à persistência de curto prazo, observa-se que as estimativas de $\beta$ são similares entre os mercados, sendo o mercado de milho o que apresenta maior persistência de curto prazo, ou seja, um choque na volatilidade em $t-1$ tem maior efeito sobre a volatilidade no instante $t$. O mercado de trigo apresenta a segunda maior persistência de curto prazo e o mercado de soja, apesar de ser o mais sensível a choques, é aquele com menor persistência de curto prazo. Ainda assim, as estimativas de $\beta$ próximas da unidade indicam alta persistência para os três mercados, o que se reflete nos valores de persistência de longo prazo e meia-vida.

A persistência de longo prazo, representada por $\vartheta$, apresenta algumas mudanças em relação a sua equivalente de curto prazo. Observa-se que o mercado de trigo apresenta a maior persistência de longo prazo, isto é, dado um choque na volatilidade, seus efeitos tendem a permanecer por mais dias neste mercado, como também é observado no valor da meia-vida $(v)$. Choques no 
mercado de trigo levam mais de 120 dias para ter seus efeitos reduzidos em $50 \%$. Para o mercado de milho, com a segunda maior persistência de longo prazo, os efeitos de um choque na volatilidade levam 96 dias para terem seus efeitos reduzidos em $50 \%$. Mesmo para o mercado de soja, que apresenta a menor persistência, um choque leva 56 dias para ter seus efeitos reduzidos em $50 \%$.

O mercado de soja foi o único a apresentar estimativas significativas de $\gamma$, ou seja, é o único dos três mercados a apresentar assimetria na volatilidade dos retornos. Além disso, nota-se que essa estimativa é negativa, o que denota a presença de efeitos de inventário. Esse resultado traz evidências de que os níveis de estoques de soja estão baixos, de modo que o aumento na demanda por soja, com subsequente aumento de preços, leva a uma maior volatilidade, quando comparado com uma redução dos preços. Esse comportamento decorre da interpretação do mercado da possibilidade de falta de estoques deste produto.

As estimativas associadas aos parâmetros das variáveis binárias sazonais $\left(\omega_{1}, \omega_{2}, \omega_{3}\right)$ permitem analisar o comportamento da volatilidade dos mercados estudados ao longo do ano. é possível observar que o mercado de milho possui maior volatilidade no segundo trimestre, período próximo ao plantio deste produto, que normalmente se inicia em abril. No mercado de soja, a volatilidade é maior no terceiro trimestre, pouco antes da colheita do grão, que se inicia geralmente em setembro. Já para o mercado de trigo, o período de maior volatilidade é o primeiro trimestre, que não compreende um período característico deste mercado, uma vez que o plantio do trigo de inverno ocorre por volta de junho e sua colheita entre final de setembro e início de outubro.

Quanto à análise dos parâmetros responsáveis por captar a ação de investidores financeiros sobre os mercados agrícolas, as estimativas de $\theta$, que representam a ação dos hedgers, foram estatisticamente significativas para os mercados de milho e soja aos níveis de $5 \%$ e $1 \%$, respectivamente. Uma vez que, para os dois mercados, as estimativas foram negativas, pode-se inferir que, quanto maior a atuação dos hedgers, menor a volatilidade nos mercados à vista de milho e soja. Também é possível afirmar que o mercado de milho é o mais afetado pela ação dos hedgers, pois apresenta maiores valores das estimativas de $\theta$.

As estimativas do parâmetro $\delta$, que representa a ação dos especuladores, foram estatisticamente significativas apenas para o mercado de milho, ao nível de 5\%. Nota-se que esta estimativa é positiva, ou seja, quanto maior a atuação dos especuladores, maior a volatilidade no mercado à vista de milho no período estudado.

A fim de verificar a evolução do impacto de hedgers e especuladores ao longo do período estudado, os modelos foram estimados recursivamente utilizando uma janela móvel de 1.008 observações (quatro anos de dados diários, em base 252). A Figura 2 apresenta a evolução no tempo do parâmetro $\theta$ nos mercados de milho, soja e trigo, em que a linha preta indica a estimativa do parâmetro, a linha cinza indica o p-valor, e a linha pontilhada delimita o nível de $10 \%$ de significância. Assim, os casos em que a linha cinza (p-valor) está abaixo da linha pontilhada, a estimativa de $\theta$ é estatisticamente significativa a $10 \%$. é possível observar que a ação de hedgers tem impacto significativo sobre a volatilidade nos três mercados estudados em distintos momentos do período de análise.

Para o mercado de milho, a ação de hedgers tem impacto significativo em di- 
versas ocasiões entre 2004 e 2006, alguns períodos pontuais em 2009 e 2010, e mais intensamente após 2012. é interessante comparar estas informações com o observado na Figura 1-(a), pois nos períodos em que os preços deste mercado estiveram em seu maior patamar a ação destes agentes não teve impacto sobre a volatilidade.

No mercado de soja, o impacto significativo da ação de hedgers é mais intenso entre 2004, 2009 e 2015, mas também ocorre em momentos pontuais em outros anos. A Figura 1 (b) permite observar picos negativos dos retornos deste mercado nestes anos.

Por fim, no mercado de trigo a ação de hedgers tem impacto significativo entre 2004 e 2006, e em momentos pontuais de 2010 e 2015. Como pode ser observado na Figura 1 (c), nos momentos que a série de preços possui os menores valores a ação destes agentes é significativa.

Também é possível verificar que as estimativas de $\theta$ possuem os maiores valores no mercado de trigo e os menores valores no mercado de milho. Além disso, a atuação de hedgers tem um efeito de redução da volatilidade nos três mercados antes de 2008, momento de forte expansão da economia mundial, e após 2012. Contudo, dentro deste intervalo de tempo, a atuação destes agentes aumenta a volatilidade dos mercados de milho, soja e trigo, o que pode estar associada ao aumento no número de investidores financeiros nos mercados de commodities agrícolas após a crise financeira de 2008. Como demonstrado por Helbling et al. (2008), Balestro \& Lourenço (2014), investimentos em commodities são bastante atrativos por apresentarem correlação negativa com os demais mercados, e correlação positiva com a inflação. Essas características atraem investidores que buscam diversificar suas carteiras após a crise.

Figura 2: Evolução temporal do parâmetro $\theta$ nos mercados de milho, soja e trigo dos EUA, representativo do impacto dos hedgers

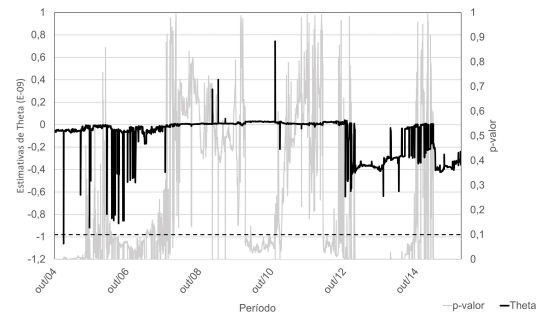

(a) Mercado de milho

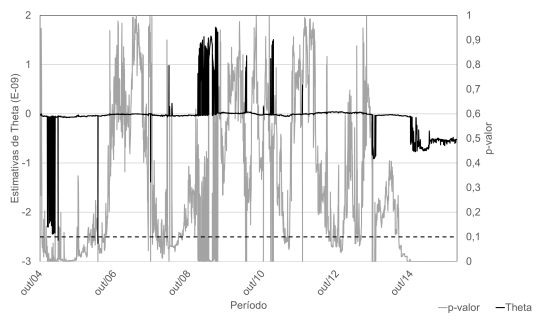

(b) Mercado de soja

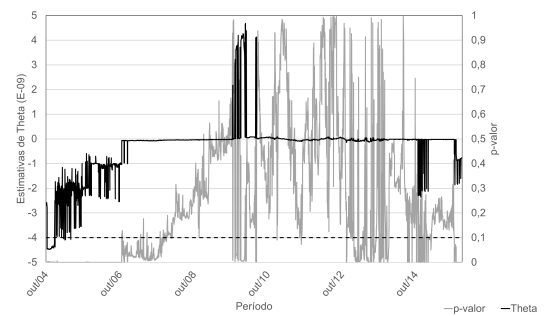

(c) Mercado de trigo

A Figura 3 apresenta a evolução no tempo do impacto dos especuladores, representado pelo parâmetro $\delta$, para os mercados de milho, soja e trigo. Nova- 
mente, a linha preta indica a estimativa do parâmetro, a linha cinza o p-valor, e a linha pontilhada delimita o nível de 10\% de significância. Quando a linha cinza se encontra abaixo da linha pontilhada, a estimativa de $\delta$ é significativa a $10 \%$.

Para o mercado de milho, a ação de especuladores tem impacto significativo entre 2004 e 2008, e a partir de 2013, assim como em momentos pontuais em 2009 e 2010. No caso do mercado de soja, a ação de especuladores tem impacto significativo em alguns meses de 2005, em 2009 e em 2015. Por fim, no mercado de trigo, a ação de especuladores é significativa entre 2004 e o final de 2006, em 2010, e em alguns períodos de 2015.

Observa-se comportamento contrário ao que ocorreu com a ação de hedgers. Anteriormente a 2008 e após 2012 (antes e depois da crise financeira), a maior atuação de especuladores tem como efeito o aumento da volatilidade nos três mercados, mas entre estes anos a maior atuação de especuladores reduz a volatilidade dos mercados de milho, soja e trigo, assim como demonstrado por Kim (2015). Por fim, nota-se que as estimativas de $\delta$ foram maiores no mercado de soja e menores no mercado de trigo, ou seja, são maiores no mercado que possui assimetrias e que é afetado por efeitos de inventário, e menores no mercado em que a ação dos hedgers tem maior impacto.

Figura 3: Evolução temporal do parâmetro $\delta$ nos mercados de milho, soja e trigo dos EUA, representativo do impacto dos especuladores

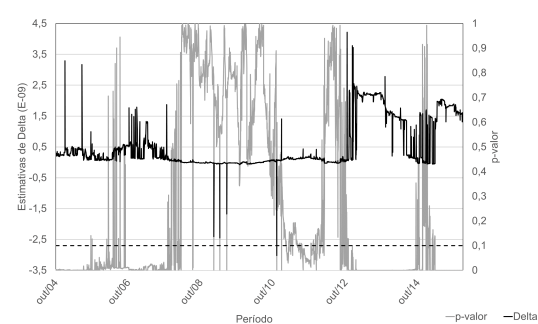

(a) Mercado de milho

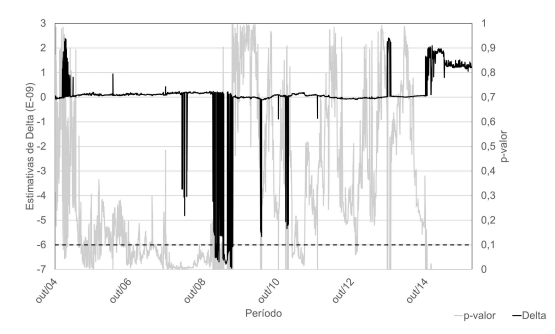

(b) Mercado de soja

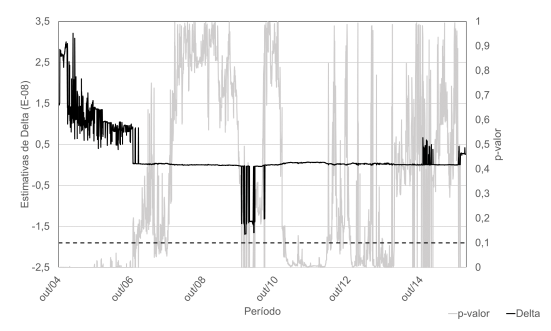

(c) Mercado de trigo

Verificou-se, portanto, que as variáveis responsáveis por captar a ação de hedgers e especuladores foram significativas apenas para o mercado de milho, que apresenta a maior persistência de curto prazo. Além disso, a ação de hedgers também se mostrou significativa para o mercado de soja, que é o mais afetado por choques de curto prazo. As estimativas recursivas permitem observar que o momento pós crise financeira de 2008 apresenta impacto significativo desses agentes em todos os mercados, porém em sentido inverso ao que apresentam nos demais momentos, isto é, a maior atuação dos hedgers tem 
como efeito o aumento da volatilidade, e a maior atuação dos especuladores tem como efeito a redução da volatilidade nos mercados de milho, soja e trigo no período analisado neste trabalho.

\subsection{Modelos de volatilidade condicional multivariados}

Após a análise do impacto da ação de hedgers e especuladores sobre a volatilidade condicional nos mercados de milho, soja e trigo nos Estados Unidos, ainda se considerou a questão acerca da transmissão de volatilidade entre estes mercados. Como os mercados de milho, soja e trigo têm características de complementariedade sendo, portanto, interligados, suas volatilidades tendem a ser transmitidas de um mercado para o outro. Deste modo, o impacto sobre a volatilidade que foi creditado a hedgers e especuladores pode ser, na realidade, um efeito de transbordamento de volatilidade. Assim, nesta seção serão estimados modelos de volatilidade condicional multivariados a fim de verificar o comportamento das correlações entre os mercados estudados nos momentos em que a ação de hedgers e especuladores se mostrou significativa.

Para calcular as inter-relações nos mercados de milho, soja e trigo, adotouse um modelo multivariado $\operatorname{BEKK}(1,1)$, com ordenação destes mercados sob os subíndices 1, 2 e 3, respectivamente. A Tabela 3 apresenta as estimativas dos parâmetros do modelo de volatilidade condicional multivariado para as séries dos retornos à vista dos mercados de milho, soja e trigo no período de janeiro de 2000 a dezembro de 2015.

Os elementos das diagonais principais das matrizes $A\left(a_{i i}, a_{j j}\right)$ e $B\left(b_{i i}, b_{j j}\right)$ capturam os efeitos ARCH e GARCH de cada mercado, já que os elementos diagonais na matriz $A$ medem os efeitos dos choques passados dentro dos próprios mercados, e os elementos diagonais da matriz B mensuram os efeitos da própria volatilidade passada sobre a volatilidade presente. Os elementos fora da diagonal principal $\left(a_{i j}, b_{i j}\right)$ capturam as interações entre as commodities. Os parâmetros $a_{i j}$ capturam os efeitos que choques no mercado $i$ têm sobre a volatilidade dos retornos de $j$, ou seja, se $a_{i j}$ é estatisticamente significativo, choques em $i$ afetam a volatilidade de $j$. De forma semelhante, os parâmetros $b_{i j}$ capturam a transmissão de volatilidade de $i$ para $j$.

As estimativas significativas de $a_{12}$ e $a_{21}$ indicam que choques no mercado de milho afetam a volatilidade no mercado de soja e vice-versa. Além disso, $a_{23}$ sugere que choques no mercado de soja afetam a volatilidade no mercado de trigo, assim como $a_{31}$ indica que choques no mercado de trigo afetam a volatilidade no mercado de milho. Analisando a transmissão de volatilidade entre estes mercados, verifica-se que há um efeito bidirecional entre milhotrigo $\left(b_{13}, b_{31}\right)$ e soja-trigo $\left(b_{23}, b_{32}\right)$. Também há transmissão de volatilidade do mercado de soja para o mercado de milho $\left(b_{21}\right)$.

A análise das variâncias e correlações destes mercados permite avaliar de que forma estas relações evoluem ao longo do tempo, além de permitir verificar se o impacto da ação de hedgers e especuladores consiste em uma questão de transmissão de volatilidade ou se é, de fato, reflexo da atuação destes agentes sobre a volatilidade dos mercados estudados. Na Figura 4 são apresentadas as volatilidades estimadas dos mercados de milho, soja e trigo. A Figura 5 demonstra a dinâmica de correlação entre estes três mercados.

é possível observar que, no mercado de milho, há três picos de volatilidade, aproximadamente, com similar intensidade, em 2004, 2008 e 2014, anos em que ocorrem aumentos expressivos de preço neste mercado. Como pode ser 
Figura 4: Variância dos mercados de milho, soja e trigo dos EUA

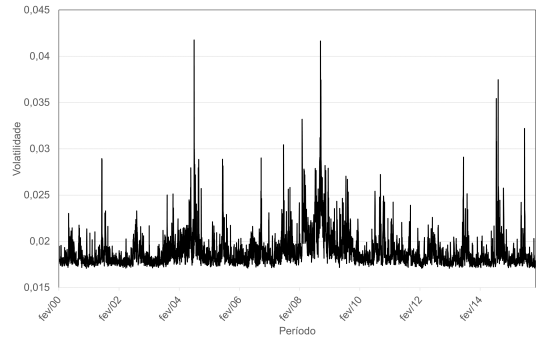

(a) Variância milho

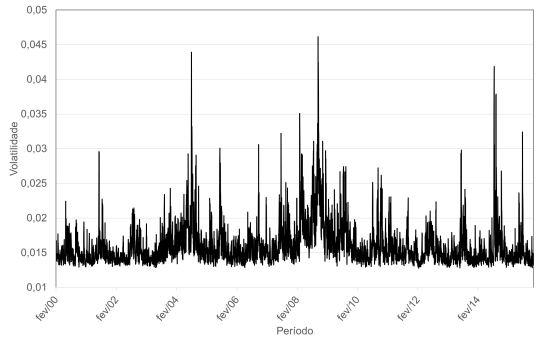

(b) Variância soja

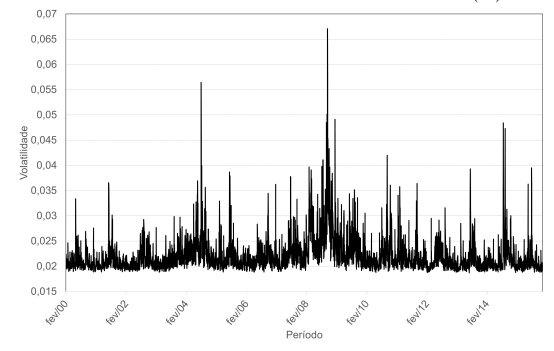

(c) Variância trigo

Figura 5: Correlação entre os mercados de milho, soja e trigo dos EUA

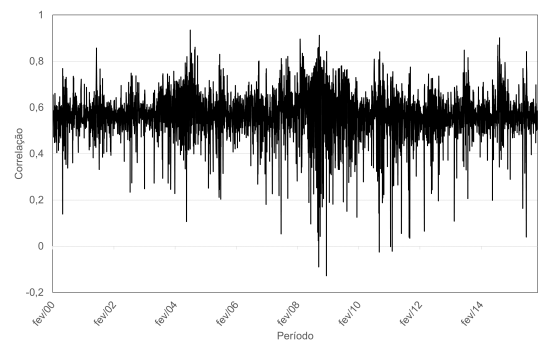

(a) Correlação milho-soja

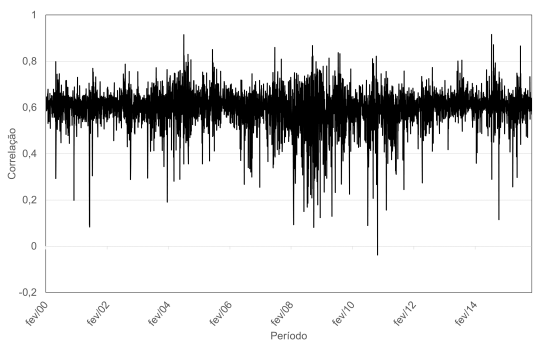

(b) Correlação milho-trigo

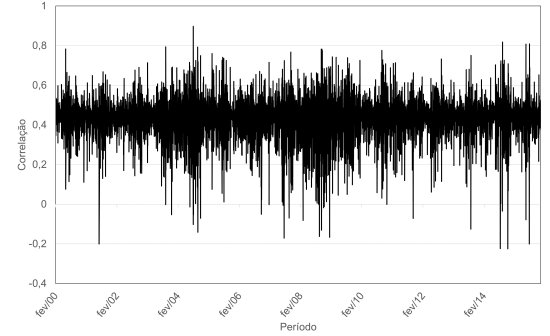

(c) Correlação soja-trigo 
Tabela 3: Estimativas dos parâmetros dos modelos $\operatorname{BEKK}(1,1)$

\begin{tabular}{c|c|c}
\hline & Estimativa & Estatística t \\
\hline$c_{11}$ & $0,013101^{* * *}$ & 14,6401 \\
\hline$c_{12}$ & 0,011423 & 1,2637 \\
\hline$c_{13}$ & $0,007259^{* * *}$ & 5,6745 \\
\hline$c_{22}$ & 0,000394 & 0,3335 \\
\hline$c_{23}$ & 0,000412 & 0,1915 \\
\hline$c_{33}$ & $-0,014678^{* * *}$ & $-21,3278$ \\
\hline$a_{11}$ & $-0,260350^{* * *}$ & $-5,0122$ \\
\hline$a_{12}$ & $-0,111120^{* *}$ & $-2,3620$ \\
\hline$a_{13}$ & 0,056423 & 0,9041 \\
\hline$a_{21}$ & $0,217512^{* * *}$ & 5,4839 \\
\hline$a_{22}$ & $0,342969^{* * *}$ & 9,8683 \\
\hline$a_{23}$ & $0,078639^{*}$ & 1,6651 \\
\hline$a_{31}$ & $0,050145^{*}$ & 1,6937 \\
\hline$a_{32}$ & 0,016833 & 0,7591 \\
\hline$a_{33}$ & $-0,336682^{* * *}$ & $-9,9502$ \\
\hline$b_{11}$ & $-0,620229^{* * *}$ & 15,6358 \\
\hline$b_{12}$ & $-0,097448$ & $-0,9312$ \\
\hline$b_{13}$ & $-0,570564^{* * *}$ & $-13,7150$ \\
\hline$b_{21}$ & $-0,449511^{* * *}$ & $-6,0533$ \\
\hline$b_{22}$ & $-0,101503$ & $-1,4179$ \\
\hline$b_{23}$ & $-0,438622^{* * *}$ & $-4,3435$ \\
\hline$b_{31}$ & $0,445539^{* * *}$ & 6,6167 \\
\hline$b_{32}$ & $0,552569^{* * *}$ & 8,3848 \\
\hline$b_{33}$ & $0,693400^{* * *}$ & 10,8037 \\
\hline Nota: $\left.{ }^{*}\right),\left({ }^{* *}\right),(* *)$ indicam significância \\
\hline estatística a $10 \%, 5 \% \mathrm{e} 1 \%$, respectivamente. \\
\hline & & \\
\hline & & \\
\hline & 0 & \\
\hline
\end{tabular}

observado na Figura 5, estes são os anos em que a correlação entre os mercados de soja e trigo diminui. Porém, ao observar as Figuras 2 (a) e 3 (a) nota-se que estes aumentos de volatilidade coincidem com momentos em que a ação de hedgers e especuladores é significativa neste mercado.

O primeiro aumento de volatilidade mais acentuado no mercado de soja ocorre por volta de 2001; em seguida, por volta de 2004 e em 2008 ocorre o maior aumento de volatilidade do período estudado, seguido por novos aumentos expressivos em 2014. Assim como ocorre com o mercado de milho, os picos de volatilidade correspondem aos momentos em que a correlação entre os mercados de milho e trigo decresce, chegando a se tornar inversa no caso soja-trigo, como apresentado na Figura 5. Por outro lado, estes são períodos em que a ação de hedgers e especuladores é significativa, como se pode verificar nas Figuras 2 (b) e 3 (b).

A volatilidade no mercado de trigo apresenta comportamento semelhante ao dos demais mercados, ainda que a correlação entre eles seja menor ou inversa durante estes picos, como pode ser observado na Figura 5. Soma-se a isso o fato de, assim como nos mercados de milho e soja, esses serem períodos em que a ação de hedgers e especuladores é significativa, como demonstrado nas Figuras 2 - (c) e 3 - (c).

Pode-se concluir que, embora ocorra um efeito transbordamento de volati- 
lidade nos mercados de grãos dos Estados Unidos, momentos em que a volatilidade destes mercados aumenta coincidem com os em que a correlação entre os mercados diminui, ao mesmo tempo que a ação de hedgers e especuladores se torna significativa. Assim, esses aumentos de volatilidade podem estar associados à ação dos agentes financeiros, e não às relações entre os mercados de grãos.

\section{Conclusão}

Este trabalho avaliou o impacto da ação de hedgers e especuladores sobre a volatilidade dos retornos dos preços à vista do milho, soja e trigo nos Estados Unidos entre 2000 e 2015 a partir de modelos de volatilidade condicional univariados da família GARCH e multivariados BEKK-GARCH. A ação desses agentes foi considerada como variável exógena na equação da variância condicional de modelos GARCH, estimados inclusive de forma recursiva para capturar alterações dos impactos ao longo do tempo. Considerou-se também modelos multivariados de volatilidade, como o BEKK-GARCH, para mensurar efeitos de transmissão de volatilidade entre os mercados de grãos considerados.

Os resultados mostram que, para as três commodities, hedgers e especuladores têm impacto significativo na volatilidade dos retornos. As estimativas recursivas indicaram que a ação destes agentes foi relevante especialmente após a crise financeira de 2008, quando se observou efeito inverso ao de outros períodos, isto é, o aumento da atuação dos hedgers teve como consequência o aumento da volatilidade, enquanto o aumento da atuação dos especuladores teve como resultado a redução na volatilidade nos mercados. Além disso, embora ocorra um efeito transbordamento de volatilidade nos mercados de grãos dos Estados Unidos, momentos em que o impacto de hedge e especulação se tornam significativos estão associados com uma redução na correlação intermercados. Como a volatilidade é uma informação crucial na geração de estratégias de gestão de risco (hedge), os resultados desse trabalho sugerem sua aplicação no gerenciamento de carteiras de investimento em commodities, sobretudo àquelas operadas com mecanismos de proteção, tais como a determinação de limites para o risco de mercado (value-at-risk). Ainda, trabalhos futuros podem incluir a avaliação para os mercados brasileiros de produtos agrícolas a fim de verificar qual o impacto de hedgers e especuladores em um país emergente.

\section{Referências Bibliográficas}

Andreasson, P., Bekiros, S., Nguyen, D. K. \& Uddin, G. S. (2016), 'Impact of speculation and economic uncertainty on commodity markets', International Review of Financial Analysis 43 (C), p. 115-127.

URL: URL: https://doi.org/10.1016/j.irfa.2015.11.005

Balestro, M. V. \& Lourenço, L. C. (2014), Notas para uma análise da financeirização do agronegócio: além da volatilidade dos preços das commodities, in A. M. Buainain, E. Alves, J. M. da Silveira \& Z. Navarro, eds, 'O mundo rural no Brasil do século 21: a formação de um novo padrão agrário e agrícola', number 4, Embrapa, pp. p. 241-266. 
Bessada, O. (2003), O mercado de derivativos financeiros, 2 edn, Record.

Bessembinder, H. \& Seguin, P. J. (1993), 'Price volatility, trading volume, and market depth: evidence from futures markets', Journal of Financial and Quantitative Analysis 28(1), p. 21-39.

Bohl, M., Siklos, P. \& Wellenreuther, C. (2018), 'Speculative activity and returns volatility of Chinese agricultural commodity futures', Journal of Asian Economics 54, p. 69-91.

Bohl, M. T. \& Stephan, P. M. (2013), 'Does futures speculation destabilize spot prices? New evidence for commodity markets', Journal of Agricultural and Applied Economics 45(4), p. 595-616.

Bollerslev, T. (1986), 'Generalized autoregressive conditional heteroskedasticity', Journal of Econometrics 31(3), p. 307-327.

Bollerslev, T., Engle, R. \& Wooldridge, J. (1988), 'A capital asset pricing model with time-varying covariances', Journal of Political Economy 96(1), p. 116131.

Brooks, C. (2008), Introductory econometrics for finance, 2 edn, Cambridge University Press, New York.

Bueno, R. D. L. (2011), Econometria de séries temporais, 2 edn, Cengage Learning, São Paulo.

Capelle-Blancard, G. \& Coulibaly, D. (2011), 'Index trading and agricultural commodity prices: a panel Granger causality analysis', International Economics 126-127, p. 51-71.

Carpantier, J.-F. (2010), Commodities inventory effect, Discussion Paper 40, Ottignies-Louvain-Ia-Neuve.

Engle, R. (2002), 'Dynamic conditional correlation: a simple class of multivariate generalized autoregressive conditional heteroskedasticity models', Journal of Business E Economic Statistics 20(3), p. 339-350.

Engle, R. F. (1982), 'Autoregressive conditional heteroscedasticity with estimates of the variance of United Kingdom inflation', Econometrica 50(4), p. 987-1007.

Engle, R. F. \& Kroner, K. F. (1995), 'Multivariate simultaneous generalized ARCH', Econometric Theory 11(1), p. 122-150.

Garcia, P., Leuthold, R. M. \& Zapata, H. (1986), 'Lead-lag relationships between trading volume and price variability: new evidence', The Journal of Futures Markets 6(1), p. 1-10.

Harris, R. \& Sollis, R. (2003), Applied time series modelling and forecasting, forecasting, John Wiley \& Sons, New Jersey.

Helbling, T., Mercer-Blackman, V. \& Cheng, K. (2008), 'Commodity boom: riding a wave', Finance $\mathcal{E}$ Development $45(1)$, p. 10-15. 
Henriques, D. B. (2008), 'Price volatility adds to worry on U.S. farms', The New York Times . Disponível em: <https://www.nytimes.com/2008/04/22/business/22commodity.html>. Acesso em: 13 dez. 2019.

Kim, A. (2015), 'Does futures speculation destabilize commodity markets?', The Journal of Futures Markets 35(8), p. 696-714.

Kim, J. H. \& Doucouliagos, H. (2005), Realized volatility and correlation in grain futures markets: testing for spill-over effects, Working paper, Department of Econometrics and Business Statistics of Monash University. Disponível em: <https://papers.ssrn.com/sol3/papers.cfm?abstract_id=791264>. Acesso em: 13 dez. 2019.

Leuthold, R. M. (1983), 'Commercial use and speculative measures of the livestock commodity futures markets', The Journal of Futures Markets 3(2), p. 113-135.

Lucia, J. J. \& Pardo, A. (2010), 'On measuring speculative and hedging activities in futures markets from volume and open interest data', Applied Economics 42(12), p. 1549-1557.

Malliaris, A. G. \& Urrutia, J. L. (1996), 'Linkages between agricultural commodity futures contracts', The Journal of Futures Markets 16(5), p. 595-609.

Manera, M., Nicolini, M. \& Vignati, I. (2013), 'Futures price volatility in commodities markets: the role of short term vs long term speculation', Working Paper. Disponível em: $<$ https://papers.ssrn.com/sol3/papers.cfm?abstract_id=2277355>. Acesso em: 13 dez. 2019.

Musunuru, N. (2014), 'Modeling price volatility linkages between corn and wheat: a multivariate GARCH estimation', International Advances in Economic Research 20(3), p. 269-280.

Paula, N. M., Santos, V. F. \& Pereira, W. S. (2015), 'A financeirização das commodities agrícolas e o sistema agroalimentar', Estudos, Sociedade e Agricultura 23(2), p. 294-314.

Rinden, S. E. (2015), The impact of speculation in commodity futures on food prices, Master's thesis, dissertação de Mestrado, University of Agder.

Rutledge, D. J. S. (1978), Trading volume and price variability: new evidence on the price effects of speculation, in 'Proceedings of the International Futures Trading Seminar, Chicago, May', pp. p. 160-174.

Santos, V. F. (2018), Impacto de hedge e especulação sobre a volatilidade dos mercados de commodities agrícolas: um estudo empírico para os EUA e Brasil, dissertação de mestrado, Instituto de Economia, Universidade Estadual de Campinas, Campinas, SP, Brasil.

Silveira, R. L. F., Maciel, L. \& Ballini, R. (2014), 'Derivativos sobre commodities influenciam a volatilidade dos preços à vista? Uma análise nos mercados de boi gordo e café arábica no Brasil', Revista de Economia e Sociologia Rural 52(3), p. 417-436. 
Silveira, R. L. F., Maciel, L., Mattos, F. \& Ballini, R. (2017), 'Volatility persistence and inventory effect in grain futures markets: evidence from a recursive model', Revista de Administraç ao 52, p. 403-418.

Teixeira, M. A. (1992), Mercados futuros: fundamentos e características operacionais, Bolsa de Mercadorias \& Futuros, São Paulo.

Tsay, R. S. (2005), Analysis of financial time series, 2 edn, John Wiley \& Sons.

Zakoian, J. M. (1994), 'Threshold heteroskedastic models', Journal of Economic Dynamics and Control 18(5), p. 931-955. 